\title{
PARTICIPAÇÃO EM UM GRUPO DE ESCALADA COMO UMA PRÁTICA DE LAZER $^{1}$
}

Recebido em: $15 / 06 / 2015$

Aceito em: 25/11/2015

Gabriel Rocha Vargas ${ }^{2}$

Dirceu S. Silva ${ }^{3}$

Silvia Cristina Franco Amaral ${ }^{4}$

Universidade Estadual de Campinas (UNICAMP)

Campinas - SP - Brasil

RESUMO: Analisamos as configurações da participação dos sujeitos em um grupo de escalada, focando a prática engajada e a construção de sentidos particulares a esse meio. Tal prática torna-se um potencial vetor de um lazer que pode ser caracterizado como significativo. Assim, o objetivo é investigar as práticas de escalada exercidas no âmbito do Grupo de Escalada Esportiva da Unicamp (GEEU). Foi empreendida uma observação participante ao longo de dezoito meses em campo. Para auxiliar na compreensão das múltiplas facetas do grupo de escalada, buscamos um modelo teórico que traz fundamentos que dialogam extensamente com o visto e o não visto em campo: a Serious Leisure Perspective de Robert Stebbins. Utilizamos as categorias definidas por esse modelo para discutir e contextualizar as práticas do grupo. A se constitui como uma cultura corporal com suas próprias atitudes, crenças, valores, práticas e expectativas.

PALAVRAS CHAVE: Atividades de Lazer. Esportes. Grupos Populacionais.

\section{LEISURE AND PARTICIPATION ON A CLIMBING GROUP}

ABSTRACT: Focusing on the engaged practice of climbing as an unrestricted pursuit, we look for spaces of meaning construction attached to the leisure experience. The objective is to investigate the meanings of practices in a Grupo de Escalada Esportiva da Unicamp (GGEU). It was realized, then, a participant observation over eighteen months on field. To assist in the understanding the multiple facets of the climbing

\footnotetext{
${ }^{1}$ Pesquisa Financiada pelo CNPq.

2 Professor da Rede Estadual de Ensino do Estado de São Paulo. Mestre em Educação Física pela Unicamp

${ }^{3}$ Mestre em Educação Física pela Universidade Federal do Espírito Santo. Doutorando em Educação Física na Unicamp.

${ }^{4}$ Livre docente pela Unicamp. Professora da Faculdade de Educação Física da Unicamp.
} 
Silvia Cristina F. Amaral

group, we sought a theoretical model that brings grounds that widely dialogues with the seen and not seen in the fieldwork: the Robert Stebbins's Serious Leisure Perspective. We make use of the categories defined by this model to discuss the practices of the climbing group in a process of contextualization through a dialogue with elements of climbing incorporated in field research. Thus, we show that the climb, as a whole, is a body culture with their own attitudes, beliefs, values, practices and expectations.

KEYWORDS: Leisure Activities. Sports. Population Groups.

\section{Introdução}

Nesse trabalho, analisamos a participação espontânea de indivíduos em uma determinada prática - a escalada. Podemos compreender, aqui, a escalada como uma prática central. Ou seja, partimos do pressuposto de que sua ação essencial - a ascensão pela rocha - é apenas o núcleo de um universo composto por diversas ações, significados e conflitos. Esses elementos vagueiam ao redor deste núcleo, alimentando a vivência rotineira dessa modalidade e por ela também sendo alimentados. Assim, o engajamento a uma atividade específica de lazer (como a escalada ou tantas outras) não é restrita ao seu exercício, e tampouco pode ser explicada analisando apenas a ação da prática central isoladamente.

Assim, para discutir o engajamento numa atividade de lazer, analisamos alguns aspectos essenciais do Grupo de Escalada Esportiva e Montanhismo da Unicamp GEEU - por meio de trabalho de observação participante junto ao grupo. Ao longo do trabalho de campo, as observações constantemente remetiam aos pressupostos da Serious Leisure Perspective (SLP), em especial ao “serious leisure” (STEBBINS, 1992, 2007). De maneira preliminar, entendemos que alguns dos participantes, que já estavam inseridos naquele universo, relacionavam-se com a escalada por meio de um engajamento que não é efêmero, e sim, substancialmente engajado. Havia ainda os 
na fluência do conhecimento próprio à escalada que os mais experientes demonstram.

Foi, desta forma, que procuramos responder a questão: qual o significado da escalada para os praticantes do Grupo de Escalada Esportiva da Unicamp (GEEU)?

Nosso objetivo foi investigar as práticas de escalada exercidas no âmbito do Grupo de Escalada Esportiva e Montanhismo da Unicamp (GEEU).

\section{Métodos}

Foi realizada uma observação participante ao longo de dezoito meses, em uma convivência com os sujeitos que visou a compreensão aprofundada desse universo. Adicionalmente, foram conduzidas oito entrevistas com membros do GEEU (seis homens e duas mulheres, com idades entre 24 e 43 anos) em que algumas informações específicas, que não emergiram espontaneamente em campo, puderam ser melhor exploradas. As entrevistas foram realizadas procurando sempre manter um caráter informal, mais flexível do que o roteiro semi-estruturado. Ao longo do texto, encontram-se tanto passagens dos cadernos de campo (destacadas entre aspas e sem referências) e trechos das entrevistas (destacadas no texto e mencionando a letra de identificação do interlocutor).

\section{O grupo de escalada}

O Grupo de Escalada Esportiva e Montanhismo da Unicamp - GEEU - é um grupo aberto, independente, autônomo e autogestionado, formado por dezenas de praticantes de escalada que interagem de maneira próxima, reunidos pelo interesse e 
Silvia Cristina F. Amaral

pelo espaço em comum. A sede do grupo é o "Muro de Escalada Vitor Negrete", uma parede com cerca de oito metros de altura e dez de largura, cravejada de agarras artificiais de resina plástica. Fica localizado em uma das faces do prédio da biblioteca da Faculdade de Educação Física - FEF - da Universidade Estadual de Campinas Unicamp. Entre os integrantes, o termo "GEEU" faz referência tanto ao grupo em si quanto ao espaço apropriado por este. O espaço físico do GEEU é a "casa” do grupo, o lócus no qual este universo se consolida. Mas o muro não “está lá desde sempre”, como brincou um iniciante, referindo-se ao trabalho voluntário na construção e manutenção do muro. Desde a fundação do grupo, em 1993, este espaço passou por um processo de apropriação e transformação, a partir de intervenções quase sempre promovidas e executadas pelos próprios integrantes do grupo por meio de ações voluntárias.

Nem todos os membros do GEEU possuem vínculo direto com a Unicamp, embora a maior parte continue sendo composta pelos estudantes de variados níveis e áreas, bem como alguns funcionários e servidores dessa instituição. São todos, em grande parte, residentes fixos ou temporários de Campinas e região. Isso reflete na identidade do grupo.

Os novatos chegam ao GEEU através de diversos caminhos. Em nossas observações, o evento mais comum é um iniciante, ao se apresentar, dizer que "sempre passo aqui e vejo vocês, e resolvi experimentar" ou "tem um amigo meu que escala aqui, o fulano, ele falou para eu vir tentar”. Algumas vezes o novato já possui alguma experiência na escalada, ou até mesmo é de fato um escalador experiente e vai ao GEEU

\footnotetext{
${ }^{5}$ Assim batizado em 2006, em homenagem ao então recém falecido escalador e antigo membro do GEEU.
} 

da escalada. O iniciante será recebido com algumas informações sobre o GEEU e orientações sobre a afiliação ao grupo. Ele deverá assinar um termo de responsabilidade, contendo as regras mais importantes da participação. Após as três primeiras idas ao GEEU, é pedido que o novato contribua com a semestralidade de $\mathrm{R} \$ 50,00$. Para aqueles que já fazem parte do grupo, incentiva-se que o pagamento seja realizado assim que o semestre tenha início.

O comum é que o muro abra à noite. As monitorias iniciam às $18 \mathrm{~h}$ e vão até 20h30min. Em alguns dias, há ainda um horário extra, que se estende até as $22 \mathrm{~h}$. Em alguns semestres há também as monitorias diurnas, em alguns dias da semana. A abertura e o funcionamento do muro cabem aos monitores, organizados sempre em duplas ou trios. Os monitores são membros do grupo que se voluntariam a tal responsabilidade no início de cada semestre letivo da universidade.

Entre aqueles que já fazem parte do grupo, a interação é próxima. Há um predominante clima descontraído, com muitas piadas e brincadeiras, que alterna com as discussões sobre segurança, técnicas de escalada, relatos e eventos ocorridos na rocha e inúmeros outros assuntos. Transitar pelo muro significa também transitar em pequenos grupos, focos de conversas. Tudo ocorre ao mesmo tempo: uns estão descansando, outros fazendo segurança na corda para os que escalam. Ainda há os que só passaram para "dar um oi". Mas entre aqueles que não se efetivaram como integrantes do grupo, evidentemente, o entrosamento não é tão imediato. Novatos, ao chegarem (especialmente se forem iniciantes), costumam permanecer por alguns minutos a certa distância, apenas observando do quê exatamente se trata aquele conjunto de pessoas e cordas. 
Silvia Cristina F. Amaral

A princípio, o distanciamento do ambiente natural não é um fator tão sentido

pelos escaladores. Para Marinho (2001, p. 33)

[...] as pessoas têm encarado como comum a escalada em muros artificiais; entretanto, o trazer as dificuldades na natureza para a cidade, muitas vezes, tem sido tratado meramente como uma consequência. Um fácil acesso e uma comodidade com maior segurança $[\ldots]$.

A facilidade de acessar o ambiente artificial favorece o contato com as paredes

de escalada, mas não necessariamente desvincula o participante da escalada em rocha.

Para C. e F, respectivamente,

[...] não tenho tempo durante a semana [...] porque eu tenho que trabalhar. No GEEU eu posso vir durante a semana, treinar, para quando chegar o final de semana eu estar bem e conseguir fazer as coisas na rocha, escalar bem, ter força, resistência.

[...] pra rocha você sabe, é sempre mais complicado. Você não gasta uma ou duas horas. Você gasta um turno. Você gasta uma tarde, um dia, pra fazer todo o rolê. Tem que levar comida, aquela coisa toda.

A rocha atrai mais pelas suas características técnicas do pelo seu caráter:

[...] a rocha não foi preparada pra você escalar ela, ela simplesmente está lá. Então a pessoa pode usar a criatividade e achar coisas que no plástico[resina] você não tem, isso traz mais complexidade. Escalada em rocha é mais complexo, eu diria, em todos os aspectos (W.).

Assim, mais importante do que estar inserido na natureza e afastado do urbano, aparentemente a escalada em rocha é mais atrativa que a escalada em ambientes artificiais pelas vias mais altas, desafiadoras, e por não terem as restrições da escalada em resina. Para alguns, a escalada envolve um espectro mais amplo de atividades:

[...] eu penso que escalar, ele abrange a rocha, abrange o ambiente artificial, abrange qualquer progressão vertical. Tem gente que fala que a travessia [horizontal] também é escalada [...]. Eu penso que a escalada abrange tudo, se você subir aqui, já tá fazendo uma escalada, tudo isso é escalada (W.). 
O GEEU, em suas reformas, adota o comum método de distribuir as agarras mais ou menos aleatoriamente na parede, para que em seguida as vias sejam criadas. Fitas coloridas são coladas próximo às agarras que fazem parte de uma determinada via. Existem maneiras de atribuir uma graduação de dificuldade à escalada. No Brasil utilizamos o próprio sistema brasileiro, no qual as vias mais fáceis são graduadas em $3^{\circ}$ grau, progredindo na seguinte escala: $3^{\circ}, 3^{\circ} \sup , 4^{\circ}, 4^{\circ} \sup , 5^{\circ}, 5^{\circ} \sup , 6^{\circ}, 6 \sup$, e em seguida 7a, 7b, 7c, 8a, 8b, 8c, 9a, 9b, 9c, 10a e assim sucessivamente. Para os boulders, a graduação dos problemas começa em V0, seguido por V1, V2, V3, V4 e assim por diante. Embora essas graduações aparentem ser numericamente precisas, sua atribuição é muito subjetiva e muitas vezes torna-se alvo de divergências e discussões confusas. Dentre as diversas variáveis envolvidas na avaliação do grau de dificuldade de uma via ou problema, estão o tipo de movimentação, força, resistência e flexibilidade empregadas, características da rocha, homogeneidade da sequência de movimentos, etc. Mas a dificuldade da escalada, em considerável parte, não reside apenas nos aspectos físicos. Fatores como a altura em relação ao solo, a distância desde a última proteção, a exposição a uma queda, a possibilidade de que a rocha quebre ou o equipamento falhe são desafios mentais, que em inúmeros momentos superam o desafio físico. Os escaladores referem-se à capacidade de lidar com o medo e a ansiedade como "psico". Se, por um lado, "ter um bom psico" é uma qualidade apreciada, por outro, um escalador forte pode simplesmente não conseguir guiar uma via condizente ao seu nível caso sinta-se inseguro, "com o psico abalado", como dizem.

O equipamento do escalador varia, evidentemente, conforme a modalidade ou as modalidades que este pratica. Entre os materiais mais importantes estão a corda dinâmica (elástica), as costuras (par de mosquetões ligados por uma fita que conectam a 

aderência e ajuste bem apertado). Há vários outros equipamentos que cumprem determinadas funções, como os freios, mosquetões diversos, fitas solteiras, o carbonato de magnésio (para manter as mãos livres de suor), etc.

Por ser o grande fator em comum entre os praticantes, as conversas circulam majoritariamente pelo assunto da escalada, especialmente se for entre escaladores desconhecidos ou de grupos diferentes. Relatos sobre acontecimentos ocorridos nos picos (locais de prática da escalada), exceto casos que envolvam algum incidente, são contados com bom humor. Trocas de informações técnicas, opiniões sobre produtos e equipamentos também são comuns. Outro assunto frequente na base das vias é relativo à segurança - um dos aspectos mais importantes dessa atividade - ao qual muita atenção é destacada. Mas, sem dúvida, muito do que se ouve na base das vias é a troca de betas, ou seja, dicas passadas àquele que escala pelos mais experientes ou pelos que já conhecem a via.

O termo beta é tão difundido entre os escaladores que seu uso extrapola sua aplicação original. Não raro pudemos ouvir frases como "vou te dar um beta bom para chegar no Visual" (referindo-se a um caminho mais fácil para ir ao Visual das Águas, um pico na cidade de Bragança Paulista - SP), ou, em outro exemplo, “me dá aí uns betas de umas lojas de madeira e parafuso". Esses termos são uma amostra do léxico particular ao universo da escalada que incluem muitas outras palavras e significados que confundem leigos e iniciantes. Torna-se uma linguagem quase universal neste meio e é parte dos bens simbólicos particulares da escalada.

Os chamados picos são os locais, geralmente em meio à natureza, em que a escalada acontece em sua forma mais essencial. Dificilmente um iniciante que chega ao 
GEEU "vai pra rocha" logo em suas primeiras semanas. Mais do que ter equipamento, conhecimento técnico e habilidades mínimas e saber como chegar aos locais, é necessário certo entrosamento com pelo menos alguns participantes do grupo. Conversas que incluem frases como "você já foi pra rocha?" ou "fui pra rocha pela primeira vez, fulano me levou" são ouvidas entre iniciantes que efetivamente aderem ao grupo. A ida à rocha não é exatamente simples nem mesmo para os mais experientes, pois existem algumas barreiras. Uma delas é em relação à disponibilidade de equipamentos e ao transporte. Para J., "[...] o grande problema que me acompanha desde que eu comecei a escalar é a questão do transporte, aqui no grupo não tem esse problema, aqui a gente tem carro [...]". Como os picos são distantes de Barão Geraldo $^{6}$, uma brincadeira recorrente no grupo é dizer que "o carro é um dos equipos mais importantes na escalada".

Aqueles que vão à rocha costumam acertar horários e caronas em encontros no muro, através da internet ou em contatos pessoais. Geralmente os escaladores já têm seus parceiros mais habituais, mas é muito comum estar com alguém com quem nunca se escalou junto, antes.

Em Campinas, um dos locais mais frequentados pelos escaladores em geral é uma pedreira no bairro Jardim Garcia. Desativada há pelo menos 25 anos, foi apropriada como um espaço de lazer não só pelos escaladores, mas também pelos aeromodelistas e, sobretudo, pelos moradores do entorno, que vão à pedreira para caminhar, correr, andar de bicicleta ou simplesmente para passear e observar os

\footnotetext{
${ }^{6}$ Barão Geraldo é o distrito de Campinas em que se localiza a Unicamp e onde moram muitos estudantes da universidade, e, consequentemente, grande parte dos integrantes do GEEU.
} 
Silvia Cristina F. Amaral

escaladores e aeromodelos. Embora seja bastante frequentada devido ao seu fácil acesso e conte com dezenas de vias de vários níveis de dificuldade, a "pedreira do Garcia" não é o ambiente favorito dos escaladores. Talvez pelo aspecto urbano da paisagem, ou talvez pela sensação de artificialidade da rocha dinamitada.

Geralmente é nesses espaços que temos a oportunidade de nos aproximarmos de escaladores que não fazem parte do GEEU. Na pedreira do Jardim Garcia é habitual encontrar e conversar com escaladores de Campinas e de outras cidades da região que acabam por tornarem-se conhecidos. Mas é ao visitar os picos mais conhecidos e frequentados que alguns fatores interessantes sobre a relação entre os escaladores são revelados. Há uma tendência à identificação amigável entre os escaladores, devido aos interesses em comum e, também, por questões relativas à segurança:

[...] não é porque é da mesma tribo, [mas] eu sinto pelo menos que a gente começa a agir com benevolência. Começa a agir pensando que você pode precisar da outra pessoa que está compartilhando o mesmo ambiente, é como se mudar para uma casa nova, sabe? Você não vai maltratar seu vizinho que você nem conhece! Pelo contrário, você quer ser simpático, quer criar amizade, um laço forte no local. $\mathrm{Na}$ escalada, por mais que seja rápido, que dure só um dia, às vezes um segundo ao menos, mas que pode estar sua vida nisso (V.).

Outro fator muito mencionado envolve o "mundo pequeno" da escalada, que revela parte do significado de encontrar, seja na rocha ou fora dela, outros escaladores:

[...] é um universo muito pequeno, eu acho que facilita o contato, que as pessoas se conheçam. Hoje em dia eu acho que isso mudou um pouco, porque direto a gente chega em alguns picos de escalada, de uns dois anos pra cá, e percebi que a gente chega nos lugares e nem sempre a gente conhece todo mundo. Aliás, na verdade, tem muitas pessoas novas, antes não. Até uns dois anos atrás sempre a gente sabia tudo o que estava acontecendo em todos os lugares, a gente conhecia todas as pessoas (B.).

[...] em outras regiões ou fora do Brasil eu conheço algumas pessoas que se eu não fosse para lá eu encontraria. Eu viajo geralmente sem 
parceiro e encontro os parceiros nos lugares. Geralmente são pessoas que eu conheci nesses lugares mesmo que acabaram virando parceiros (J.).

Embora as experiências aparentem ser positivas, isso não corresponde totalmente à realidade. Muitas vezes essa esperada hospitalidade não é correspondida, como mencionou C. em entrevista:

[...] eu senti que quando eu estive [nas montanhas do estado do Rio de Janeiro] não fui bem recebida, não sei o porquê, mas não fui bem recebida como eu fui aqui em São Paulo ou em Minas. Não escalei junto com eles, porém ao chegar na rocha os caras foram meio ríspidos, nem chegaram para cumprimentar, bem diferente daqui ou de Minas, onde as pessoas logo vem conversar quando você chega [...].

Um dos integrantes do GEEU contou-nos que não é raro encontrar escaladores, sobretudo da cidade de São Paulo, que talvez por não integrarem um grupo organizado (logo, não habituados a uma prática mais coletiva), "tomam conta das vias, abrem gazebos na base e ficam lá como se estivessem na casa deles, ou na academia [de escalada] e ninguém mais consegue escalar ali”.

Esse mesmo integrante, em outra ocasião, também nos explicou que certa hierarquização pode ser esperada entre os praticantes, ditada pela experiência, habilidade e influência no meio: "você chega lá no meio de um monte de caras fortes, que mandam nono, décimo grau, e ninguém nem te olha, nem cumprimenta. Você é um nada". E prosseguiu, em tom de brincadeira, dizendo que "aí você entra numa via forte, manda a via e os caras já começam a olhar diferente". Mas essas ocasiões são raras nunca chegamos a presenciar pessoalmente algum conflito do tipo.

Todavia, a diferenciação entre escaladores de variados níveis de habilidade e experiência constituem uma hierarquia pouco conflituosa dentro da escalada. Na 
Silvia Cristina F. Amaral

escalada esportiva, por exemplo, cada um escala a via que corresponde ao seu próprio nível, ou talvez ou um pouco abaixo, para "aquecer", ou um pouco acima, para “malhar". Por isso, os iniciantes não se sentem acuados por terem que dividir um espaço estrito com aqueles que carregam maior status de grupo. Os escaladores não costumam mencionar tal hierarquia. Existe um respeito e admiração voltados aos mais experientes aos nomes mais reconhecidos, tal qual como em qualquer outro esporte. Mas, talvez pela característica de "mundo pequeno" da escalada, o distanciamento entre escaladores de variados níveis se perca nas relações estabelecidas entre eles. Mas, ainda assim, algo pode ser observado, como relatou L. em entrevista:

Acho que existe hierarquia de conhecimento. O pessoal mais antigo tem a última palavra, se o cara falar que isso é assim ou assado a gente costuma respeitar. Mas costuma questionar, né, porque não é hierarquia militar - o cara fala isso e todo mundo obedece. A gente questiona... mas é por tempo de escalada e experiência. Se eu vejo um cara que é mais velho que eu falando que eu estou fazendo uma coisa errada, eu obedeço a pessoa ou sigo as orientações dela. [...] Os mais velhos são mais... mandões (risos).

Tal status de grupo é edificado no cenário da escalada de uma maneira que diz muito sobre essa atividade. Especialmente por não ser uma prática amplamente difundida ${ }^{7}$, aqueles que são mais fluentes na linguagem de valores e símbolos desse universo podem ser imediatamente reconhecidos como legítimos "nativos" da escalada.

\footnotetext{
${ }^{7}$ De maneira superficial, os escaladores (em geral) julgam benéfico que a escalada se popularize, mas sem saber ponderar quais as consequências disso. Alguns praticantes são contrários a esse movimento, temendo aumento do número de acidentes e deterioração dos picos. Sem maiores argumentos, alguns entrevistados abordaram brevemente a questão da difusão da escalada. Segundo L., "O pessoal tem medo dos acidentes, tal, de divulgar muito o esporte, mas acho que isso não resolve nenhum problema". Para C., "[...] muita gente no Brasil não quer que o esporte se popularize. [...] Acho que o bem que essa pessoa faz [praticando escalada] é bem maior que um eventual impacto sobre a natureza pela prática do esporte".
} 
Silvia Cristina F. Amaral

Um censo promovido por Marski Filho (2009) obteve 739 participações ${ }^{8}$ (embora, sem dúvida, o número real de escaladores no Brasil seja maior $\left.{ }^{9}\right)$. Diferentemente de muitos dos esportes mais populares, os nomes mais reconhecidos da escalada no Brasil são sujeitos comuns, com quem poderíamos escalar lado a lado em uma tarde na rocha. São reconhecidos não só pelas suas habilidades e experiência, mas, também, pela influência e pela própria difusão pessoal no meio, estando sempre presentes nos festivais, competições, vídeos divulgados na internet, etc. Alguns desses inclusive são membros do GEEU e visitam o muro com relativa frequência. Ao acompanhá-los nos picos, eles assumem o papel de vetores de contato com outros praticantes. Com isso, cria-se uma rede de relações ao redor do interesse central da atividade em questão. Há os parceiros de escalada que são amigos; os parceiros de escalada; os amigos dos parceiros de escalada; os escaladores de outras regiões que encontramos nos picos e seus parceiros; e assim por diante. Um observador atento poderá identificar a imersão no universo da escalada por um sujeito sem vê-lo "mandar" uma via; basta estar atento à maneira com que ele se relaciona com os demais escaladores e a amplitude de sua rede de relações.

Atualmente, essa rede estende-se para os meios virtuais, através de redes sociais na internet. Nesses meios, os escaladores trocam informações e conteúdos relacionados à escalada, transparecendo uma identificação através da qual desejam ser reconhecidos como escaladores, aventureiros, destemidos amantes da natureza e do outdoor.

\footnotetext{
${ }^{8}$ Alguns dos dados mais significativos que podem ser extraídos desse censo indicam que a maior parte dos escaladores são homens entre 20 e 30 anos com graduação completa. Para mais informações, consultar os dados colhidos por Marski Filho (2009).

${ }^{9}$ Logo antes do fechamento desse texto, um dos membros do grupo mencionou, em uma conversa, uma estimativa de cerca de trinta mil praticantes de escalada no Brasil.
} 
A adesão à escalada também é demonstrada através das roupas que os escaladores usam. É muito comum ver que, nos picos e em eventos, a indumentária favorita é aquela que estampa logotipos de marcas relacionadas à escalada e atividades outdoor em geral, conferindo um aspecto de prontidão à aventura. Porém, no cotidiano daqueles integrantes do GEEU que têm algum vínculo com a Unicamp e que durante o dia transitam entre as salas de aula, laboratórios e o muro, isso não é algo muito pronunciado. São vestuários técnicos, ou seja, roupas feitas com materiais e cortes especiais cuja função sobrepõe-se à aparência: não seria de estranhar, em um dia frio, vê-los indo a um bar após o trabalho vestidos como se estivessem prontos para uma travessia na cordilheira dos Andes. Com isso, cria-se um fetiche e uma necessidade de consumo ao redor de marcas universalmente conhecidas nesse universo, como North Face, Mammoth, Arc'teryx, Mountain Hardwear, Columbia, etc. Por serem equipamentos de alto custo, os escaladores podem recorrer a outras estratégias para serem reconhecidos como tais.

Para Magnani (2002, p. 22), estas são maneiras para que eles se reconheçam, “como portadores dos mesmos símbolos que remetem a gostos, orientações, valores, hábitos de consumo e modos de vida semelhantes". Assim, mais do que uma identificação reconhecível entre os iniciados no meio, essa ostentação parece também querer revelar aos leigos da escalada que o indivíduo que carrega essas marcas e símbolos detém uma identidade cunhada fora de uma situação de normalidade, como se quisesse dizer "eu sou escalador".

Existe um código de ética no universo da escalada que compreende regras escritas e não escritas. Documentos divulgados pelos órgãos competentes da área, como a União Internacional das Associações de Alpinismo - UIAA, órgão máximo da 
Silvia Cristina F. Amaral

escalada mundial, ou por organizações em outros níveis ${ }^{10}$, regulamentam, orientam e alertam sobre diversos aspectos da relação entre praticantes, a prática e o ambiente. Questões como a conservação dos locais naturais próximos aos picos, regras para abertura e registro de vias, normas referentes aos equipamentos, etc., estão entre os temas abordados e em relação aos quais os escaladores devem estar atentos. A ética da escalada, de maneira informal, também influencia o convívio de escaladores nas vias, nos picos e arredores. Assim, atitudes como saber aguardar o momento certo para escalar, estar atento à sua segurança e a dos outros e preservar as vias, dentre várias outras observações, tornam a ética da escalada também uma linguagem universal entre os praticantes dessa atividade.

Assim vemos que a escalada, como um todo, constitui uma cultura com suas próprias atitudes, crenças, valores, práticas e expectativas. Logo, ela assume a forma de um mundo social, que segundo Unruh $^{11}$ (apud STEBBINS, 2007, p. 12), é

[...] uma unidade de organização social difusa e amorfa [...]. Geralmente é mais abrangente que grupos ou organizações, de maneira que esses mundos não são necessariamente definidos por limites formais, listas de afiliados, ou território espacial [...]. Um mundo social deve ser visto como uma constelação internamente reconhecível de atores, organizações, eventos e práticas que se agregam em uma perceptível esfera de interesse e envolvimento para os participantes. Caracteristicamente, um mundo social não apresenta uma estrutura autoritária de poder centralizado é delimitado [...] por uma comunicação efetiva, e não por território em por filiação formal a um grupo (tradução nossa).

\footnotetext{
${ }^{10}$ Disponível em: < http://www.femerj.org/sobre-a-femerj/etica $>$ para diversos documentos deste caráter.

${ }^{11}$ UNRUH, David. The nature of social worlds. The Pacific Sociological Review, v. 23, n. 3, p. 271-296, 1980.
} 
Neste mundo social, como dito, há elementos reconhecíveis entre os participantes, que assumem uma significação muito mais completa do que quando vistos por observadores externos. A atração pela natureza, pelas dificuldades das ascensões verticais, a exposição ao risco e toda a linguagem e símbolos são, e de certa forma só podem ser, plenamente compreendidos por aqueles que se embrenham em suas aventuras pela escalada.

\section{Configurações do Lazer e Participação no/do GEEU}

Uma vez apresentadas as principais características da formação, da constituição e do funcionamento do grupo de escalada, partimos para uma análise de alguns elementos que caracterizam as particularidades da experiência de lazer oportunizada pelo ambiente do GEEU. Para auxiliar na compreensão das múltiplas facetas do grupo de escalada, recuperamos um modelo teórico que traz fundamentos que dialogam extensamente com o visto e o não visto no trabalho de campo: a Serious Leisure Perspective (SLP), que foi introduzida pela obra de Robert A. Stebbins (1982, 1992, 2007). Segundo o autor, a SLP é definida como o quadro teórico que sintetiza três principais formas de lazer, mostrando, cada uma, suas distintivas características, similaridades e interrelações (STEBBINS, 2007, 2009). Essas três principais formas são o serious leisure, casual leisure e project-based leisure.

Destacamos, nesse trabalho, a categoria serious leisure por esta relacionar-se com algumas formas de participação manifestadas pelo praticante em relação ao grupo de escalada. O serious leisure pode ser definido como a prática sistemática de uma atividade amadora, de hobby ou voluntária, que é suficientemente substancial e 
interessante para o participante a ponto de esse desenvolver uma carreira em que ele poderá adquirir e expressar suas habilidades e conhecimentos especiais (STEBBINS, 1992, 2007). O termo serious era recorrente entre os pesquisados de Stebbins e indica zelo, importância, valor, influência, esmero; e se traduzido para sério, ganharia a conotação de indolência, falta de alegria, pesar e ansiedade. Todavia, de uma maneira ou outra essas últimas características também possam estar presentes em uma atividade de serious leisure, como o próprio Stebbins (2007) indica.

Aqueles que demonstram um pronunciado envolvimento com o universo da escalada aproximam-se do serious leisure, categoria cujas características determinantes foram compiladas por Stebbins a partir de suas pesquisas empíricas e, evidentemente, seus detalhes variam conforme a atividade, o grupo, o local e o tempo na qual esta acontece. O serious leisure divide-se entre três formas de participação: amadores, hobbyistas e voluntários. Os Amadores podem ser encontrados em atividades ligadas às artes, ciências, esportes e entretenimento. Stebbins (1992) define como amadora aquela atividade em que há uma homóloga profissional. Isso inclui também o público que consome a produção daquele amador ou do profissional, criando um sistema conhecido como "profissional - amador - público" (STEBBINS, 2007). A diferença entre os amadores e hobbyistas é que esses não contam com o sistema profissional - amador público, ou mesmo não possuem o homólogo profissional. E se possuem um público, ou seja, alguém que consuma sua produção, este será pequeno - como alguém que tenha como hobby o aquarismo, e, eventualmente, venda alguns peixes ou construa aquários sobre encomenda. É entre os hobbyistas que majoritariamente situamos a escalada, caso queiramos alocá-la nas classificações de Stebbins. Assim como nas demais formas de serious leisure, ser adepto a um hobby requer um investimento de recursos, como tempo 
e dinheiro (VARGAS, 2010). Já os voluntários são indivíduos que oferecem, sistematicamente, algum tipo de ajuda (ou vários tipos de ajudas) não coagida, de maneira formal ou informal, recebendo ou não alguma contrapartida (STEBBINS, 2007). É possível que exista uma dificuldade em compreendermos o que realmente seria o voluntariado como lazer, seja se pensarmos nas concepções mais tradicionais de lazer, por um lado, ou se pensarmos no voluntariado como uma necessidade social decorrente de deficiências da gestão pública, por outro. Geralmente, também associamos o termo à oferta de ajuda a uma grave necessidade, evidenciando um tom que dificilmente poderia relacionar-se com o lazer. Mas como veremos ao longo do texto, o voluntariado também é parte integrante da experiência de lazer oportunizada pelo GEEU.

\section{Benefícios em Relação à Escalada e ao GEEU}

Stebbins (2007) elenca uma série de possíveis benefícios individuais oriundos das práticas de serious leisure. Para o autor, as motivações para o envolvimento em uma atividade de serious leisure residem nas retribuições (reward), que superam os custos (investimentos de tempo, dinheiro e superação de outras possíveis barreiras) (STEBBINS, 2007, 2009). A seguir, tais retribuições serão apresentadas em um diálogo com a experiência de campo e as entrevistas.

A valorização pessoal (personal enrichment) ocorre através de experiências queridas, como as lembranças de bons momentos vividos ao escalar ou junto ao grupo, dando sentido à própria existência como escalador. Isso está diretamente relacionado com a auto-realização (self-actualization), que corresponde ao desenvolvimento de habilidades e conhecimentos necessários e específicos à escalada que podem ser 
Silvia Cristina F. Amaral

colocados em prática, e a auto-expressão (self-expression), que corresponde à oportunidade de expressar as habilidades, conhecimentos e experiências já desenvolvidas e acumuladas. Isso pode ser observado constantemente, quando o escalador conquista uma rota mais difícil.

Essas progressões também estão intrinsecamente vinculadas à autoimagem (selfimage), dada, aqui, pelo desenvolvimento de uma identidade associada à participação em uma atividade de serious leisure. No caso, envolver-se com a escalada e alcançar feitos típicos de escaladores faz com que o participante sinta-se um escalador. Isso remete, ainda, ao próximo benefício: a satisfação própria (self-gratification), ou seja, a combinação entre simples diversão, de caráter mais superficial, e uma satisfação mais profunda e substancial. Essa união é fruto da prática da escalada e de todos os significados provenientes dela. Como os entrevistados declararam,

Pra mim, [espero] diversão. Tem gente que diversão é ir a uma festa ou ir a uma loja do shopping. Diversão para mim é estar com os amigos na montanha (C.).

Stebbins $(2007,2009)$ também aponta para a recreação ou regeneração (recreation ou regeneration), em que, para alguns, é consequência direta da prática da escalada:

Pra mim, escalar ta envolvido também com qualidade de vida. Acho que é mais isso, é uma atividade esportiva, e você acaba melhorando sua alimentação, sua condição física, regulando seus horários, acho que isso me atrai bastante (R.).

A recreação ou regeneração assemelha-se aos conceitos funcionalistas que articulam o lazer com as mazelas do cotidiano, servindo como "válvula de escape". No senso comum dos sujeitos, é muitas vezes a maneira como encontram para justificar seu 
tempo de lazer, embora não corresponda de fato às suas expectativas e benefícios.

Dificilmente os aficionados pela escalada ou por qualquer outra prática de serious leisure argumentarão que sua atividade é apenas um descanso, dado que eles sabem, direta ou indiretamente, que sua prática preferencial envolve uma série de elementos especiais, que entendemos como os elementos significantes.

A superação destes desafios impostos pela natureza ou por si relacionam-se com uma das características do serious leisure, que Stebbins $(2001 ; 2007)$ denomina perseverança (persevere), ou a necessidade de perseverar na atividade. Todo o desenvolvimento pessoal de cada sujeito ao longo de sua trajetória na inserção e participação em uma prática de lazer significativo é representado pelo que Stebbins (2001, 2007) nos apresenta como carreira de lazer (leisure career), o que é uma das mais importantes características do serious leisure. As carreiras de lazer são um caminho percorrido pelo participante ao longo de seu envolvimento com a atividade de serious leisure. Stebbins (2004) indica algumas etapas da carreira de lazer: início, desenvolvimento, estabelecimento, manutenção e, se for o caso, declínio. Segundo o autor, as fronteiras entre esses estágios são imprecisas e imperceptíveis. O início dura o tempo necessário para que seja enraizado o interesse pela atividade (STEBBINS, 2004). Entre os iniciantes da escalada, isso pode acontecer logo após a sua primeira experiência, ou após um maior período acompanhando a namorada escaladora, por exemplo. O quão veloz ou não é tal enraizamento não tem relação aparente com o posterior engajamento. Observamos novatos empolgados após o primeiro dia no muro, que logo pagaram a semestralidade e diziam estar ansiosos para voltar. Porém nunca voltaram, ou voltaram apenas algumas poucas vezes. É difícil determinar por que isso acontece, pois ao deixar o muro eles deixam também o campo da pesquisa; de qualquer 
maneira, eles não passaram pelo primeiro passo de suas carreiras de lazer. O próximo estágio é o desenvolvimento, que começa quando o interesse está enraizado e sua prática torna-se mais ou menos rotineira (STEBBINS, 2004). É uma etapa simples de observar, pois é quando, em campo, as "caras novas" começam a tornar-se familiares e nomes começam a ser decorados; o participante, que já não é mais tão iniciante, aprende a fazer a segurança e talvez tenha suas primeiras experiências em ambiente natural, na rocha. $\mathrm{Na}$ fase do estabelecimento, o indivíduo já aprendeu os princípios básicos daquela atividade. É quando se estabelece também a identidade - algo como "sou escalador”. O participante já possui o mínimo de equipamentos necessários, é dotado de iniciativas, seja junto às ações do grupo ou em incursões à rocha, e finalmente está inserido no grupo, reconhecendo os outros participantes e sendo reconhecidos por estes (reconhecido como membro do grupo e também como escalador). É, finalmente, durante a fase de manutenção que a carreira de lazer está em pleno florescimento (STEBBINS, 2004). Incertezas iniciais sobre a inserção no grupo e na atividade já estão superadas. Nessa fase, o participante é fluente tanto na linguagem verbal e não verbal particular do universo da escalada quanto na troca de valores como experiência, conhecimentos e habilidades. O escalador também atinge relativa autonomia para tomar decisões marcantes, assumindo qual sua modalidade favorita, orientando iniciantes e sentindo-se confortável ao dividir os picos com escaladores mais fortes e experientes. Por fim, é na fase do declínio, caso haja, que o escalador abandona a atividade. Esse abandono pode ser por um longo período de tempo (afastado por vários anos) ou permanente, e ocasionado por motivos diversos. Embora tenhamos conhecido pessoas que abandonaram a escalada em algum dos outros estágios, foram pouquíssimos aqueles que entraram em declínio, depois de alcançada e estabelecida uma etapa mais 
Gabriel Rocha Vargas, Dirceu S. Silva e

Silvia Cristina F. Amaral

Participação em um Grupo de Escalada ...

desenvolvida de suas carreiras de lazer. Alguns se afastaram da prática em si, mas continuam sendo membros do grupo (pagando as semestralidades) e participam das discussões por e-mails, o que os coloca em um tipo de limbo do serious leisure. Esses sujeitos podem, talvez, manter sua inserção no universo da escalada, excetuando apenas o núcleo, que é o ato escalar.

Stebbins (2007) ainda nos apresenta as "retribuições sociais". São três formas de benefícios coletivos, resultantes da participação em um grupo ou em uma categoria de aficionados por um mesmo interesse central, ou por uma mesma manifestação de lazer significativo/serious leisure. A coesão social (social attraction) é oportunizada ao associar-se com outros participantes daquela atividade de serious leisure. É uma retribuição fundamental no cenário observado e mostrou ser um dos elementos mais importantes na participação da escalada e do GEEU como serious leisure. A realização coletiva (group accomplishment) e a contribuição para a manutenção e desenvolvimento do grupo, provenientes do esforço coletivo em realizar um projeto de serious leisure, como, por exemplo, criar e manter a existência do GEEU. O participante beneficia-se do sentimento de altruísmo, de ajudar um conjunto de ideias e interesses e de ser necessário nas ações deste coletivo. Esses aspectos mostraram-se de grande relevância no estudo do GEEU e toca as considerações centrais da presente pesquisa, ao representar a importância da participação coletiva na experiência de lazer. Ao longo do texto foram e serão apresentados elementos que justificam essa importância, a qual voltaremos a discutir diretamente nas considerações finais. 


\section{Tempo, Compromisso e Prioridades}

Marinho (2001, p. 87) alega que na prática da escalada no GEEU "não se evidencia o caráter de obrigação, nem de dever”. Porém, as observações demonstraram um cenário oposto. Como já foi discutido, o voluntariado e a preocupação com a segurança no GEEU já são claros demonstrativos de tal caráter de obrigação e dever. Para Stebbins (2007), o compromisso é uma atitude relevante em relação ao serious leisure, embora não chegue a ser um elemento definidor de tal. Ao senso comum, sentimentos de compromisso e obrigação no lazer podem parecer ilógicos (STEBBINS, 1992), mas o autor destaca o que ele chama de "compromisso positivo", ou seja, o investimento de tempo e energia no lazer dado pelos seus participantes (STEBBINS, 2007):

Depois que eu comecei a escalar, assim, de uma forma mais apaixonada, assim, né, querendo evoluir mental e fisicamente [...], isso me tomou (enfatizando) muito tempo, assim, muito tempo (F.).

Não sei se isso é assim em outro esporte, eu fico muito impressionado como muitas decisões minhas ficam envolvidas com a escalada. [...]o impacto que isso tem na sua vida é bem grande (J.).

Os entrevistados foram unânimes ao afirmarem que dedicam muito tempo (e outros recursos) ao mundo da escalada, e que essa exigência, por parte do lazer, acaba influenciando outras esferas da vida. Tal dedicação é indicativo do envolvimento do sujeito com a atividade, e aqui acredito que esse fator também seja uma das características mais relevantes do serious leisure. Ao elevar a importância de sua prática favorita no cotidiano, o sujeito possivelmente está encontrando nessa prática, então, os elementos que ele anseia para sentir-se satisfeito e em plenitude. Isso acontece pois o escalador vê-se envolvido com a escalada em diferentes momentos de sua rotina: 
De todos os finais de semana e feriados do ano, no mínimo oitenta por cento deles eu vou fazer coisas relacionadas à escalada, certamente. Bastante tempo, lendo coisas, participando de lista, discutindo com as pessoas, treinando no GEEU. Todas as noites [em 2012], todas as terças e quintas [venho] aqui no GEEU (B.).

Realmente a escalada te suga, a sua leitura, as coisas que você assiste, a questão do dinheiro, passa a ser tudo dedicado à escalada, a equipamentos e viagens, até a questão de relacionamento influencia muito (J.).

[...] a gente acaba gastando tudo o que a gente ganha na escalada, diretamente ou indiretamente, com viagem, equipamento. Investimento de dinheiro, tempo, todo final de semana ou feriado você acaba indo pra um lugar de escalada em vez de sei lá, ir passar com a família (R.).

Ao inserir-se no GEEU, o participante pode assumir algumas responsabilidades, como monitorias e ações de intervenções. A princípio, observamos que o compromisso dos sujeitos com o desejo de desenvolver as próprias habilidades não parecia ser tão evidente. De fato, não observamos um sentimento de obrigação como aquele gerado pelo clima de competição entre os ciclistas (VARGAS, 2010), que encaravam sua prática como um treino sistematizado e, para manter o condicionamento, saíam para treinar mesmo se naquele dia não estivessem com vontade. A impressão inicial era de que os escaladores atendiam muito mais, ou praticamente apenas, ao simples desejo de escalar. Mas os participantes fazem uma relação direta entre um maior desenvolvimento das habilidades e um maior desfrute da prática:

[...] se você não tá treinando, se você não tá escalando sempre, você não consegue escalar muito, então quanto mais você escala, mais você escala. As outras coisas eu acho que você consegue equilibrar mais. Eu me interesso bastante por arte, por exemplo, mas não é uma coisa que eu precise ficar todos os dias lendo ou alimentando esse desejo meu. Na escalada, já não (B.).

[Se ficasse um tempo afastado da prática de escalada] Eu tentaria compensar esse tempo que eu não poderia vir escalar praticando de alguma forma, ou em casa ou de algum jeito, eu ia tentar treinar sempre pra não perder o nível que eu estou atualmente (R.). 
Silvia Cristina F. Amaral

Mas o discurso de alguém que se afasta da prática por um período relativamente curto lamenta, também, o fato de estar ausente nas atividades tanto quanto o déficit no rendimento devido ao afastamento. Ou seja, o fato de não estar presente junto ao grupo ou nas idas aos picos, já significa, de modo geral, não ter o prazer da escalada. Isso transparece em falas como a de T., que, em resposta a um convite à rocha, disse: “[...] quero ir na pedreira esse fim de semana, faz muito tempo que eu não escalo e acho que não tô conseguindo subir nem escada. [...] Tô com saudade da turma, também". Ou também, no caso de N., que mesmo com o ombro lesionado e já afastado há meses da prática da escalada, não deixava de visitar a pedreira nos finais de semana e o muro do GEEU, para reencontrar amigos e distribuir betas das vias. Afastar-se da prática da escalada corresponde a afastar-se também desse círculo de sociabilidades. Como ocorreu com N., essas lesões às vezes não afastavam o indivíduo do grupo. Mesmo sem poder escalar, alguns deles continuavam frequentando o muro, seja para a “escalada teórica ${ }^{12}$ ", ou apenas para "dar um 'oi' pra galera”. Um dos membros assumiu um horário de monitoria, mesmo afastado por ordem médica devido a uma lesão - "o médico disse que eu não posso escalar, mas não falou nada sobre fazer segurança", brincou.

Isso indica que dificilmente alguém irá ao muro do GEEU para "treinar ${ }^{13}$ ", sem vontade, apenas pela obrigação de manter ou progredir em seu rendimento atlético. $\mathrm{O}$ compromisso com a escalada é demonstrado, então, através do empenho na prática em

\footnotetext{
${ }^{12}$ Não chega a ser uma gíria, mas é uma brincadeira referente àqueles que ficam conversando e "dando betas" sem escalar.

13 "Treinar", aliás, não é um termo que alcança o consenso no grupo. Alguns, independente do nível de habilidade, dizem que vão "escalar". Outros reservam o termo "treino" apenas à escalada em ambientes artificiais, de forma que o que se faz em ambiente natural, na rocha, é o "escalar", de fato.
} 
si, ou se preparando para ela, estudando a seu respeito, e outras atitudes do gênero (STEBBINS, 2007), que estão relacionadas tanto com a escalada em geral quanto ao GEEU. É o que Stebbins (2001, 2007) denomina por empenho (effort), uma característica do serious leisure que o participante deve empregar no desenvolvimento da prática no mundo do lazer significativo. Isto envolve aquilo que reconhecemos como os quatro valores do serious leisure que são desenvolvidos ao longo da carreira de lazer: conhecimento, treinamento, experiência e habilidade. Esses valores são adquiríveis, intercambiáveis e acumuláveis em uma prática de serious leisure. Stebbins (2007) refere-se brevemente a esses itens, mas as observações trouxeram alguns dados que auxiliam na construção desses conceitos, especialmente no que se refere à progressão que os participantes buscam em seu envolvimento com a atividade. Escaladores que estão a mais tempo envolvidos com essa prática detêm, de modo geral, mais conhecimentos sobre os variados aspectos da escalda, como usos e tipos dos equipamentos, picos, domínio da técnica, etc. A habilidade também é adquirida ao longo do tempo e envolve a superação de algumas barreiras - alguns escaladores têm mais força e resistência muscular, enquanto outros são mais leves e flexíveis; algumas vias, da mesma maneira, exigem mais força (especialmente os boulders), enquanto outras exigem movimentos mais delicados e precisos. E para cadenar uma via de graduação mais forte, habilidades deverão ser desenvolvidas através de treino e alguma dedicação. Mas, evidentemente, esse aspecto não trata apenas de capacidades corporais. Como dito, existem, além disso, muitos equipamentos para situações específicas, e muitas técnicas que são necessárias em possíveis ocasiões de emergência (acidentes, resgates, abandono de vias em caso de chuva ou falha das proteções, falha do equipamento, etc.). O domínio do uso desses elementos constitui um corpo de 
Silvia Cristina F. Amaral

conhecimentos que também exige treino para que seja incorporado e aperfeiçoado. No

caso do membro do GEEU, envolve também os demais compromissos e

responsabilidades com o grupo:

Boa parte do meu tempo livre é dedicado a isso, né. Inclusive tem outras questões rotineiras do grupo, sei lá, mandar e-mail... ver se nego não tá morrendo lá, se não tá subindo pra se matar lá de cima, essas coisas... comprar não sei o que lá, essas coisas tomam muito tempo, assim... reunião dali, reunião de cá... são coisas que eu preciso fazer mas não gosto de fazer, né? Então assim, num contexto geral, né, olhando, sei lá, organização do grupo, olhando as discussões dentro do grupo, olhando o tempo de escalada mesmo, acho que tem tomado bastante tempo, sugado bastante tempo (F.).

Entre tudo, portanto, esse compromisso é determinado pela prioridade da escalada entre as atividades cotidianas. Naturalmente, ao elevar a importância da escalada entre outras esferas da vida, alguns assuntos caem em detrimento:

Assim que cheguei ao muro, o V. veio me dizer, empolgado, que agora está com mais tempo livre e que quer escalar bastante. Falou que quer viajar para o Cipó, que quer ir na pedreira pelo menos uma vez durante a semana. Perguntei se ele não pretendia ir na casa da sua família [em outro estado], pois ele já havia comentado sobre isso. Pensou um pouco e disse algo como 'ah, to na pegada de escalar' e riu [...] (Caderno de campo, 26/05/2012).

Durante esse breve diálogo com o escalador V., foi citada a já declarada necessidade de passar alguns dias na casa de seus pais justamente para tensionar a questão da prioridade da escalada em detrimento de outros aspectos da vida. Esse embate revela um lado potencialmente conflituoso do serious leisure, em que é justamente o tal "compromisso positivo" que se torna, em dadas condições, não tão positivo para o participante ou para seus próximos. Stebbins (1992), embora não aborde tanto essa questão, menciona a interferência do envolvimento com uma prática de serious leisure nos relacionamentos pessoais, especialmente os conjugais. O atrito entre duas importantes esferas da vida é demonstrado pela fala de F.: 
Ah, não sei... eu anseio muito que eu conseguisse que minha namorada se apaixonasse também pela escalada, seria bacana, assim... porque a vida a dois é complicada. Tipo, passo muito tempo do meu tempo psicológico com ela, assim. Então seria muito legal se tivesse uma esfera [em comum] dentro da escalada, né. A gente podia, inclusive, fortalecer laços, também. Acho que seria bacana, assim. Não que os laços não sejam fortes o suficientes, enfim. É uma coisa que eu anseio bastante [...]. Ficaria mais fácil pra mim e mais fácil pra ela. Faria com que ela participasse mais no meu cotidiano e eu no do dela, também.

Stebbins (1992) também alega, brevemente, que há casos em que a estabilidade familiar é colocada em risco devido à dedicação exacerbada dispensada ao lazer, uma situação que ultrapassa a aceitação e tolerância relatadas na fala anterior. Durante o período da pesquisa, destaco três casos ocorridos com integrantes do GEEU que exemplificam a influência do universo de lazer no universo das práticas conjugais: A., que havia iniciado na escalada há pouco mais de um ano quando começou a relacionarse com alguém de fora da escalada, e pouco a pouco abandonou o GEEU; de D., que começou a escalar ao iniciar um namoro com M., que já escalava há alguns meses no GEEU; ou o caso de R., que declaradamente gostaria de estar mais presente nas idas à rocha nos finais de semana, causando um conflito de interesses com sua namorada. "Acho que vou arrumar uma namorada que escala", disse-nos R., cujo tom de brincadeira não ocultava uma preocupação real. Da mesma maneira, a prática aficionada da escalada também influencia as amizades e a relação com a família:

[...] tem sobrado muito pouco tempo pra outras coisas. Basicamente meu tempo fica em estudar... que é meu trabalho, digamos assim, é... (pensando), e... escalar, e aí, tipo, sei lá, tenho minha namorada também, minha família, que a gente conversa, a gente se vê, enfim, essas coisas. Então fica mais ou menos distribuído aí. Tem os amigos também, e tal. Ultimamente eu to com poucos amigos fora da escalada, né (F.). 
Silvia Cristina F. Amaral

Além dos relacionamentos, o hábito de priorizar a escalada também acarreta no

detrimento de outras práticas do cotidiano, ou, ainda, resultam na ressignificação delas.

Elementos destituídos de sentidos ganham novos significados ao serem associados à experiência do lazer significativo:

Eu sempre fiz yoga, antes de escalar, depois que eu comecei a escalar eu fiz slackline, comecei a correr também. Mas são coisas que eu faço para melhorar a escalada, que se eu não escalasse acho que não faria. Eu corro mais quando eu tenho uma viagem programada, então eu começo há correr um tempo antes. Eu praticava vôlei mas foi diminuindo até parar de vez e a escalada tomar o lugar, e hoje às vezes eu jogo vôlei, mas acho que não vale a pena pois eu posso machucar e deixar de escalar por causa do vôlei (J.).

Mas nem sempre o envolvimento com o serious leisure resulta em um

"descontrole" de seu alcance no cotidiano. Em vários momentos, é necessário rever as prioridades pessoais, mas que geralmente levam o lazer em consideração. O serious leisure, nesse caso, não é necessariamente excluído ou abandonado, mas sim protelado ou reposicionado.

Agora em 2012, eu me programei para fazer uma pós e também para trazer minha namorada para morar aqui em Campinas, [...] a gente tinha um projeto de se casar e ter um bebê no ano que vem, então eu coloquei outras prioridades e decidi que esse ano de 2012 era o momento de dar um tempo na escalada. Até porque se eu continuasse insistindo com a escalada podia ser que o meu corpo [lesionado] não se curasse, e eu fiquei com receio de nunca mais poder escalar. Então eu dei um tempo, mas estou voltando aos poucos, não parei totalmente. Só que durante a semana eu não tenho tempo por causa da pós, só aos domingos que eu estou livre e não são todos, mas eu pretendo escalar eternamente... e participando do GEEU (V.).

[...] escalada, se você deixar, você fica pensando o tempo todo nisso. Mas se você tem interesse em socializar com outras pessoas diferentes das do meio da escalada, conhecer lugares diferentes que não tenham a ver com a escalada, ou estudar coisas diferentes, ou que você goste do seu trabalho e queira estudar alguma coisa relacionada ao seu trabalho... você tem que de vez em quando abrir mão da escalada pra conseguir fazer essas coisas. Por exemplo, você vai fazer uma prova porque você tem interesse em fazer um mestrado, ou mesmo no meu caso, eu tava terminando a graduação. Ao longo da minha graduação eu não pude escalar no GEEU porque ele só abria à noite, ao final da 
graduação eu não pude ficar escalando porque eu tava fazendo minha monografia. Naquele período eu tive que colocar na balança e deixar a escalada de lado pra fazer aquilo que era prioridade na época. Acho que só escalada, não sei se é ruim, mas uma pessoa que faz somente uma coisa só, só pensa numa coisa, é uma pessoa chata né. Um cara que curta muito ir na igreja, sai de casa vai pro trabalho, sai do trabalho e vai pra casa e vai pra igreja, o cara só sabe falar ou no trabalho dele ou na igreja, na escalada as vezes acontece isso, e você tem que se policiar pra se inteirar em outros assuntos [...]. Eu gostaria, eu acho, de dedicar meu tempo pra outras prioridades. Antes, quando eu não escalava, eu achava meio chato assim. Eu saia com a galera e pensava "essa galera só sabe falar em escalada, mano, a galera só pensa em escalada, só pensa nisso!’. Hoje em dia isso já não me incomoda mais (B.).

Para Stebbins (2007), as atividades de lazer podem apresentar um lado obrigatório que seus participantes compreendem e vivenciam como parte do lazer. Isso é evidente nas falas dos entrevistados, e está profundamente relacionado com os fatores atitudinais da escolha do lazer e seu caráter significativo. Todavia, tal envolvimento pode não fazer sentido para o sujeito que é externo ao universo da escalada. E, como não poderia deixar de ser, a imagem do profundo envolvimento e adesão remete à relação entre lazer e trabalho ou ao próprio caráter de trabalho da prática. Como é compreendido pelos próprios participantes:

Tem gente que se apaixona pela atividade e coloca aquilo ou como atividade principal ou logo abaixo do trabalho, [em] que o trabalho é mais uma necessidade pra sobreviver, mas nem ta querendo trabalho. Por exemplo, no caso do Rodrigo [Raineri] e do Vitor Negrete, eles colocaram aquilo numa intensidade máxima, então a pessoa progride mais rápido e atinge um nível muito maior (W.).

[...] É um trabalho tipo trabalho de hobby, um trabalho gostoso. É como mexer com madeira, você não ganha a vida mexendo com madeira, mas tem gente que gosta de mexer com madeira. Mas tu encara como trabalho, senão a peça de madeira que você quer fazer não vai sair, né? [...] Acho que eu me imponho metas, e isso, assim, às vezes é meio saudável, às vezes não... Saudável porque às vezes ajuda a crescer ali dentro, mas às vezes não porque você fica sobrecarregando demais [...] com possíveis metas que ainda não foram alcançadas, ou que tão longe de serem alcançadas, enfim. Então nesse sentido, de enxergar a coisa como um trabalho acaba sendo um negativo. Mas eu entendo, eu entendo essa negatividade, eu consigo 
lidar bem com ela porque não é meu ganha-pão. Então se eu não consigo chegar eu falo "azar, eu faço outra meta, mais baixa e pronto", não preciso fazer isso (F.).

Com isso, é possível perceber que os sentimentos de obrigação e dever são comuns e aceitáveis entre os participantes, ainda que sejam encarados de algumas formas variadas. Para Stebbins (2007), obrigação é um aspecto atitudinal frequente do lazer (especialmente do serious leisure), mas sua ideia é "subconceitualizada" (STEBBINS, 2007, p. 72). Essa obrigação aceitável pode, portanto, ser parte do lazer, a qual motiva o participante devido às suas expectativas de satisfação durante a realização da atividade.

\section{Usos do GEEU}

Ao confrontar as diferentes visões dos participantes do GEEU através das falas das entrevistas e das observações em campo, evidencia-se uma gama de sentidos atribuídos à participação no grupo de escalada estudado. Em um primeiro olhar, o GEEU é um grupo de praticantes de escalada, de pessoas reunidas ao redor de um interesse central. Mas como já fora notado uma década antes, por Marinho (2001, p. 21):

No começo do surgimento do GEEU, o objetivo primeiro era o de escalar. A opção pelo lazer limitava-se ao interesse de escalar por escalar, mas, atualmente, tem se apresentado um pouco diferente. Todos os escaladores pesquisados afirmaram que o muro representa, da mesma forma, uma opção de lazer, no entanto, voltada para diversificados interesses: alguns se limitam a treinar para campeonatos; outros preferem ir ao muro só para bater papo, saber das novidades; outros, ainda, fazem do muro um ponto de encontro para ir às rochas ou a algum outro compromisso e alguns, por fim, gostam (e fazem) de tudo ao mesmo tempo. 
Como dito pela autora, o GEEU é um lócus que cumpre variados papéis na experiência de lazer de seus participantes. Os diferentes sujeitos da pesquisa demonstraram diferentes opiniões sobre seu lazer, mas sem, realmente, destoar amplamente em como esse lazer se efetua. No grupo, a prática em si da escalada, seus benefícios e suas satisfações individuais, a oportunidade de envolver-se com o voluntariado e ações construtivas, de adquirir e expressar conhecimentos, habilidades e experiências, e a possibilidade do sujeito situar-se em um meio específico com interesses em comum são fragmentos da experiência rica e idiossincrática proporcionada pela existência do mundo social do GEEU.

O esforço dessa pesquisa é apresentar o que é possível encontrar no grupo de escalada, mas outra pesquisa seria necessária para compreender o que novatos e curiosos buscam quando se dirigem ao GEEU. Já para os integrantes estabelecidos no grupo, as falas das entrevistas e, sobretudo, as observações de campo, confirmaram as palavras de Marinho (2001). Em geral, o muro é o espaço da prática da escalada, para ambientalizar-se entre outros escaladores e, de maneira secundária ou como consequência disso, é também um local para encontrar amigos ou estabelecer novos laços de amizade: para B., a escalada é, além de tudo, "um esporte muito sociável”. O relacionamento interpessoal no ambiente do muro (bem da escalada em geral) está conectado a duas características determinantes do serious leisure (STEBBINS, 2007, 2009): a existência de um ethos (unique ehtos) que emerge ao redor da atividade central e a oportunidade de o participante desenvolver uma identidade pessoal e social (distintive identity). Para Stebbins $(2007 ; 2009)$, ethos corresponde ao espírito de uma comunidade de participantes de uma determinada atividade de serious leisure, manifestado através de atitudes, práticas, valores, objetivos e crenças compartilhadas 
Silvia Cristina F. Amaral

entre esses participantes. Mais que isso, tal ethos representa uma rica subcultura - como

a que enxergamos ao olharmos todo o universo da escalada. Nesta subcultura, a partir

do ethos, oportuniza-se também a formação de uma rede de sociabilidade.

O pessoal do GEEU geralmente é muito gente boa. A escalada é uma coisa que eu gosto de fazer, mas eu também venho aqui pra parte social, né. Acho que as pessoas do grupo são muito importantes. Do meu ponto de vista, os grandes amigos que eu fiz recentemente foram na escalada... fora isso, não tenho muitas grandes novas amizades fora desse quesito [...] (L.).

Eu acho que eu escalaria mesmo que não tivesse essa parte social forte assim, eu até gosto de ir e fazer a escalada sozinho, mas eu acho que a parte social é um ponto forte também (J.).

Assim também vê Magnani (2002, p. 22) ao observar grupos de lazer, cujos integrantes “[...] vão até lá para encontrar seus iguais, exercitar-se no uso dos códigos comuns, apreciar os símbolos escolhidos para marcar as diferenças. [...] é assim que essa rede da sociabilidade vai sendo tecida". O código de ética universal, a identificação entre os praticantes, as representações visuais exprimidas nas fotografias e nos vídeos, os picos clássicos ao redor do globo, as notícias das últimas cadenas dos mitos da escalada, dentre tantos outros elementos que são universais no âmbito da escalada - e só da escalada - nos fazem pensar como as inúmeras outras atividades de serious leisure criam, igualmente, inúmeros outros universos de práticas e símbolos compartilhados em subculturas de lazer. Mas não basta apenas que os participantes estejam localizados sob a aura da escalada para que exista uma associação natural entre os sujeitos. Por se tratar de um mundo social, a escalada também conta com seus subgrupos sociais que facilitam ou distanciam a aproximação. Uma interessante observação foi feita por J., que, em entrevista, relatou:

[...] tem um espectro de escalador, [e] o tamanho da rocha é inversamente proporcional à sociabilidade, e isso é consistente em 
todos os lugares do mundo em que eu fui. Você está escalando um lugar, por exemplo, onde tem alpinismo, clássica e boulder, e todo mundo acampa em um lugar. A galera do boulder é a mais social, vive agitando, fazendo festa, tal. E isso vai de grau em grau: boulder, depois escalada esportiva, escalada tradicional, em móvel, né, e alpinismo. Isso é bem legal, assim. E eu percebi que o individualismo aumenta conforme o grau aumenta também. Acho que é uma simbiose, acho que as pessoas mais individualistas são mais propensas a se identificar com as práticas mais individualistas, e a própria prática direciona isso (J.).

Isso remete, ainda, ao aspecto da construção da identidade. Fruto de todas as demais características do serious leisure, a identidade do escalador ou praticante de escalada é praticamente uma catarse proporcionada pela experiência do lazer significativo. Curiosamente, Stebbins não dedica muita atenção a essa relevante característica. Jones (2000) alega que aquele autor negligencia a importância da identificação e, consequentemente, da identificação social que o serious leisure provê aos participantes. Não restam dúvidas sobre a construção da identidade do escalador, cunhada sobre as próprias expectativas e realizações e reconhecida pelos seus pares, bem como por aqueles que não pertencem ao universo em questão.

Adentrar o GEEU como um integrante a ponto de sentir-se plenamente parte do grupo e tendo as bases para a construção de tal identidade exige, do participante, uma inserção junto ao grupo. Alguns dos entrevistados, que atualmente são membros atuantes e participativos no GEEU, relembram suas chegadas ao grupo e o processo de inserção:

Eu achei que foi mais demorado do que eu esperava, [...] [comparado às] experiências anteriores em outros grupos. Mas foi no sentido de não estar muito à vontade com, sei lá... eu não gosto muito da parte do top-rope, e na época o boulder não tinha os colchões direito... então você precisava se enturmar mais com as pessoas pra pedir seg, compartilhar colchão e tal... Então foi mais essas coisas, eu não gostava muito da parede e da estrutura (inaudível). Eu acho que se o boulder tivesse as coisas direitinho eu ficaria mais à vontade (J.). 
Quando cheguei foi tipo, tinha umas 3 pessoas, mais ou menos, que era o R., o L. e o L. [...]. Esses caras me parecem pessoas muito legais assim. E enfim, tipo, ficava mais assim xeretando eles, né, ficar mais perto, puxava assunto na medida do possível, e tal. E foi com eles que eu fui me enturmando [...]. E eu não sei, nunca tive muita dificuldade pra me enturmar com as pessoas, assim. [...] Salvo alguns membros mais velhos [...] que você, sei lá, você tem algum certo respeito, você sente uma certa dificuldade de aproximar. Mas isso com o tempo também acabei aproximando (F.).

Além disso, devido ao GEEU ser um grupo situado em um ambiente universitário e, como falado, formado em considerável parte por pessoas vinculadas à Unicamp, também pensamos que ele é mais um espaço de sociabilidade dentro do campus. Sempre pudemos observar grupos de amigos que iam ao GEEU apenas para fazer algo diferente durante a semana, ou alguém que experimentava a escalada cedendo à insistência de algum amigo já escalador. Essas manifestações de lazer casual, tidas como uma vivência efêmera e ocasional, são distantes de todos os aspectos da experiência de lazer apresentados nesse texto. Embora, para alguns, uma permanência junto ao grupo represente também alguns sentidos importantes que não têm como interesse primordial a prática da escalada:

\begin{abstract}
Ah, acho que uma coisa que o GEEU tem como papel sem ser escalada, como grupo, ele é a mãe assim dos avulsos da Unicamp, né. Pessoal que vem fazer mestrado de outro lugar, que não conhece ninguém, pessoal que vem... tipo eu que acabei a faculdade e voltei pra Campinas... Ah, "meus amigos moram longe, pra onde eu vou?". Então GEEU é meio que uma mãe nesse sentido. Você vê muitos gringos que vão pro GEEU porque os caras estão lá perdidos, os avulsos da Unicamp, e não têm muito o que fazer e vai no GEEU, conhece a galera e acaba se enturmando com o pessoal da Unicamp, $\operatorname{assim}($ L.).
\end{abstract}

Exatamente dessa maneira, P., estudante estrangeiro ingressante em um curso de mestrado na Unicamp, encontrou no GEEU algo mais que uma nova prática corporal, mas um grupo de pessoas com quem poderia integrar-se: 
Hoje conversei um pouco com o P., um [estrangeiro] que veio ao Brasil para fazer o mestrado e que parece ter encontrado algum acolhimento no GEEU. Tem ido bastante ao muro, algumas vezes nem vai para escalar. Ele já fez alguma amizade com o H., e hoje os dois estavam chamando o pessoal para ir a um forró [...] (Caderno de campo, 27/03/2012).

E em nota mais recente, de agosto do mesmo ano:

Estava tomando café na saída do RU e encontrei o P., e parei para conversar um pouco com ele. Ele estava falando sobre alguma festa que foi com seus companheiros de laboratório, e disse que eles não são um bom grupo para sair junto, que as 'conversas são sempre chatas'. Brinquei dizendo que 'a gente da escalada é mais legal' e ele concordou rindo, dizendo que realmente gosta de sair ou viajar com o pessoal do GEEU. Nunca estive com o P. na rocha [escalando], mas ele é presença constante com o pessoal da escalada [...] (Caderno de campo, 08/08/2012).

O caso de P. é um exemplo de algo comum no GEEU, em que o muro deixa de ser o local da prática corporal e passa a ser um ponto de encontro entre amigos. Este é um fator que comprova que o GEEU é utilizado como um espaço de sociabilidade e convívio. Como ocorrido com P., os sujeitos também fogem de seus grupos de trabalho, estudos ou família, para encontrar pertencimento eu seu grupo de lazer, onde encontram outras preocupações que não aquelas do cotidiano.

\section{Considerações Finais}

Ao fim do trabalho, identificam-se quatro fatores fundamentais que configuram as práticas exercidas no GEEU como ações de lazer diferenciadas, significativas, que as situam no espaço do serious leisure: o desenvolvimento e a dedicação à prática da escalada em si; a existência de um mundo social e suas relações internas, com características particulares e os códigos e as linguagens praticadas no seu interior; a 

equilíbrio entre a influência exercida por esse fator na vida de seu participante e sua prioridade; e todo o corpo de conhecimentos necessários para que o participante possa desfrutar de todos os elementos desse universo de lazer. O serious leisure e as noções de experiência de lazer e lazer significativo mostram como essas manifestações podem, portanto, assumir um papel relevante no curso da vida do sujeito que dele participa. O lazer torna-se, assim, uma opção às tradicionais instituições da sociedade - como família, religião, trabalho, nação e etnia - como um meio formador de sentidos e significados. Nesse momento, argumentamos que, ao deixar de ser um constructo subjacente aos citados acima, o lazer ascende em uma escala de importância. Quando o sujeito desfruta de alguma forma de lazer significativo, este se torna um parâmetro destacado, mas não separado de sua vida.

De maneira geral, a Serious Leisure Perspective demonstrou, através de suas categorias, que as atividades de lazer podem variar desde ações casuais de curta duração a até compromissos empenhados ao longo da vida. O quadro teórico possui suas virtudes e fraquezas no estudo do lazer. Embora ofereça uma classificação e explicação de todas as atividades e experiências de lazer (STEBBINS, 2007), essa pretensão do autor acaba por tornar-se uma fragilidade em suas proposições. Stebbins, ao longo de sua obra, cria muitas categorias na tentativa de englobar todas as situações possíveis, acabando por gerar uma sistematização rígida e confusa em categorias estanques. Seja como for, pode-se refletir sobre manifestações de lazer (especialmente as de serious leisure) tendo em vista a SLP, mas sem necessariamente ater-se a todas as categorias criadas por Stebbins, ou destacando apenas aquelas que forem mais relevantes para cada caso. 
Após 40 anos de desenvolvimento e recebendo a maior parte de suas contribuições a partir de um mesmo estudioso, a SLP é coerente em seus argumentos e também válida, como mostramos aqui através de um diálogo com os dados de campo. Talvez falte uma profundidade crítica na obra de Stebbins, que tem teor muito descritivo e, como dito, classificatório. Ainda assim, é uma grande contribuição para a área dos estudos do lazer. É importante ressaltar que, embora não tenha um olhar tão crítico e multifacetado sobre o lazer como Rojek (1995), Stebbins deixa transparecer em sua obra que o lazer não é algo de todo positivo e benéfico. $O$ autor reconhece que o envolvimento com o serious leisure pode ocasionar consequências negativas para o participante, seja em relação à família, ao matrimônio ou ao trabalho (STEBBINS, 2007), ou em relação à atuação em práticas de serious ou casual leisure consideradas como desviantes (ROJEK, 1995; STEBBINS, 2007). Ao longo da pesquisa, procuramos agregar alguns elementos ao corpo de conhecimentos da SLP: a sugestão de Jones (2000), acerca da importância da filiação ao grupo, e uma maior atenção sobre a construção do estilo de vida, da identidade e em relação aos quatro valores do serious leisure que são desenvolvidos ao longo da carreira de lazer (conhecimento, treinamento, experiência e habilidade).

\section{REFERÊNCIAS}

JONES, Ian. A model of serious leisure identification: the case of football fandom. Leisure Studies, v. 19, n. 4, p. 283-298, 2000.

MAGNANI, José Guilherme Cantor. De perto e de dentro: notas para uma etnografia. Revista Brasileira de Ciências Sociais, v.17, n. 49, p. 11-29, 2002.

MARINHO, Alcyane. Da busca pela natureza aos ambientes artificiais: reflexões sobre a escalada esportiva. 2001. 122 f. Dissertação. Mestrado em Educação Física. Universidade Estadual de Campinas. Faculdade de Educação Física, Campinas, 2001. 
Silvia Cristina F. Amaral

MARSKI FILHO, Davi Augusto. Pesquisa sobre o Perfil do Escalador. 2009. Disponível em <http://www.marski.org/component/content/article/6-diversos-geral/210pesquisa2009>. Acesso em 02 ago. 2012.

ROJEK, Chris. Decentring Leisure: rethinking leisure theory. Londres: Sage, 1995.

STEBBINS, Robert. Serious leisure: a conceptual statement. Pacific Sociological Review, v. 25, n. 2, p. 251-272, 1982.

Amateurs, professionals and serious leisure. Montreal: McGill-Queen's University Press, 1992.

Serious leisure. Society, v. 38, n. 4, p. 53-57, 2001.

Career and life course: leisure as process. LSA Newsletter, n. 6, 2004.

. Serious leisure: a perspective for our time. New Brunskwick: Transaction Publishers, 2007.

Leisure and consumption. Common ground/separate worlds. New York: Palgrave Macmillan, 2009.

UNRUH, David. The nature of social worlds. The Pacific Sociological Review, v. 23, n. 3 , p. $271-296,1980$.

VARGAS, Gabriel Rocha. Competição e lazer no esporte: aliados ou rivais? Um estudo sobre a prática dos ciclistas competitivos amadores do município de São João del-Rei - MG. Relatório de pesquisa - Programa Institucional de Iniciação Científica. São João Del-Rei: Universidade Federal de São João del-Rei, 2010.

\section{Endereço dos Autores:}

Gabriel Rocha Vargas

Departamento de Educação Física e Humanidades

Faculdade de Educação Física, Caixa Postal 6134

Universidade Estadual de Campinas - UNICAMP

Rua Érico Veríssimo, no 701 - Cidade Universitária

Campinas - SP - 13083-851

Endereço Eletrônico: dirceu_09@yahoo.com.br

Dirceu S. Silva

Departamento de Educação Física e Humanidades Faculdade de Educação Física, Caixa Postal 6134 Universidade Estadual de Campinas - UNICAMP

Rua Érico Veríssimo, no 701 - Cidade Universitária Campinas - SP - 13083-851 
Silvia Cristina F. Amaral

Endereço Eletrônico: dirceu_09@yahoo.com.br

Silvia Cristina Franco Amaral

Departamento de Educação Física e Humanidades

Faculdade de Educação Física, Caixa Postal 6134

Universidade Estadual de Campinas - UNICAMP

Rua Érico Veríssimo, no 701 - Cidade Universitária

Campinas - SP - 13083-851

Endereço Eletrônico: scfa@fef.unicamp.br 